\section{The Road Ahead for Percutaneous Endoscopic Gastrostomy-Defiance or Deliverance}

Key words: dysphagia, tube feeding, geriatrics, nutrition, medical device

\section{(Intern Med 50: 949, 2011)}

(DOI: 10.2169/internalmedicine.50.4989)

To the Editor We do wear a favorite set of clothes for years but wash them regularly. Similarly, we use the same cups, bowls and plates but clean them after every meal. When it is impractical to wash such items, we make them disposable. We would hesitate to use a second-hand drinking straw which was washed thoroughly, let alone one which was only rinsed. In the clinical setting, an indwelling Foley catheter is changed regularly to prevent ascending infection. Most nursing homes change the patient's nasogastric tube monthly, even if the tube is not blocked. Contact lenses are not worn continuously for more than 24 hours; doing so only invites serious complications.

All of these situations seem like common sense. Thus, when someone offers to sell us clothes, crockery, cutlery, catheters and contact lenses that can be used for months without washing, we immediately are suspicious.

Yet this basic adherence to good hygiene is disregarded with the percutaneous endoscopic gastrostomy (PEG) tube. The tube is neither washed nor changed like crockery or cutlery (1). Why?

As partners in "crime", we know well the reasons. First, the adhesion between the stomach and abdominal wall is not guaranteed (2). Hence, these two structures can separate after removal of a tube, and a new tube inserted through the skin stoma may come to rest in the peritoneal cavity instead of the stomach. Second, it frequently involves tedious moving a bed-bound patient by ambulance to a hospital facility for endoscopy or radiology to check the tube position. The sky blue method is innovative, but not fool-proof (3). Third, with a patient of advanced age and frailty, the trauma and stress of the tube change can precipitate a fatal stroke or heart attack (4). Fourth is the perennial cost issue. In reality, every society has its wealthy, poor and sandwiched middle class. For the wealthy, compliance with national guidelines is never a problem. For the poor, their recourse is to use the tube till it wears out (1). For the middle class, the frequency is in between these extremes, with a tendency towards the latter as the financial burden takes its toil. In summary, our hands were tied and we did not have a better solution.

The world now has the LOOPPEG ${ }^{\circledR} 3 \mathrm{G}$ tube, easier and less risky to exchange than even the nasogastric tube (5). Do patient-advocates continue with the PEG? Should not doctors be Hippocratic and offer the best approach?

The authors state that they have no Conflict of Interest (COI).

Ah San Pang ${ }^{1}$ and Iruru Maetani ${ }^{2}$

\section{References}

1. Sartori S, Trevisani L, Nielsen I, Tassinari D, Ceccotti P, Abbasciano V. Longevity of silicone and polyurethane catheters in longterm enteral feeding via percutaneous endoscopic gastrostomy. Aliment Pharmacol Ther 17: 853-856, 2003.

2. Daniels IR, Lamparelli MJ, Chave H, Simson JN. Recurrent sigmoid volvulus treated by percutaneous endoscopic colostomy. Br J Surg 87: 1419, 2000.

3. Suzuki Y, Urashima M, Yoshida H, et al. The sky blue method as a screening test to detect misplacement of percutaneous endoscopic gastrostomy tube at exchange. Intern Med 48: 2077-2081, 2009.

4. Doshi VS, Lim JKH. Nasogastric tube induced myocardial injury -fact or coincidence? Ann Acad Med Singapore 38: 168-169, 2009.

5. Pang AS. A new feeding tube which is secure and easy to change. Singapore Med J 5: 740-742, 2009.

\footnotetext{
${ }^{1}$ Mount Alvernia Medical Centre, Singapore and ${ }^{2}$ Toho University Ohashi Medical Center, Japan Received for publication December 12, 2010; Accepted for publication January 24, 2011

Correspondence to Dr. Iruru Maetani, mtnir50637@med.toho-u.ac.jp

(C) 2011 The Japanese Society of Internal Medicine Journal Website: http://www.naika.or.jp/imindex.html
} 